\title{
Redesign and reconstruction of a steviol-biosynthetic pathway for enhanced production of steviol in Escherichia coli
}

\author{
Jun Ho Moon, Kunjoong Lee, Jun Ho Lee and Pyung Cheon Lee ${ }^{*}$ (1)
}

\begin{abstract}
Background: Steviol glycosides such as stevioside have attracted the attention of the food and beverage industry. Recently, efforts were made to produce these natural sweeteners in microorganisms using metabolic engineering. Nonetheless, the steviol titer is relatively low in metabolically engineered microorganisms, and therefore a steviol-biosynthetic pathway in heterologous microorganisms needs to be metabolically optimized. The purpose of this study was to redesign and reconstruct a steviol-biosynthetic pathway via synthetic-biology approaches in order to overproduce steviol in Escherichia coli.
\end{abstract}

Results: A genome-engineered E. coli strain, which coexpressed 5' untranslated region (UTR)-engineered geranylgeranyl diphosphate synthase, copalyl diphosphate synthase, and kaurene synthase, produced $623.6 \pm 3.0 \mathrm{mg} / \mathrm{L}$ ent-kaurene in batch fermentation. Overexpression of 5'-UTR-engineered, N-terminally modified kaurene oxidase of Arabidopsis thaliana yielded $41.4 \pm 5 \mathrm{mg} / \mathrm{L}$ ent-kaurenoic acid. Enhanced ent-kaurenoic acid production $(50.7 \pm 9.8 \mathrm{mg} / \mathrm{L})$ was achieved by increasing the cellular NADPH/NADP ${ }^{+}$ratio. The expression of a fusion protein, UtrCYP714A2-AtCPR2 derived from A. thaliana, where trCYP714A2 was 5'-UTR-engineered and N-terminally modified, gave $38.4 \pm 1.7 \mathrm{mg} / \mathrm{L}$ steviol in batch fermentation.

Conclusions: $5^{\prime}$-UTR engineering, the fusion protein approach, and redox balancing improved the steviol titer in flask fermentation and bioreactor fermentation. The expression engineering of steviol-biosynthetic enzymes and the genome engineering described here can serve as the basis for producing terpenoids_including steviol glycosides and carotenoids - in microorganisms.

Keywords: Steviol, Kaurenoic acid, Kaurene, Metabolic engineering

\section{Background}

Steviol glycosides are diterpenoid glycosides of entkaurene present in the plant Stevia rebaudiana Bertoni. Given that steviol glycosides contain no calories and taste 200-300-fold sweeter than sucrose [1], these natural sweeteners may help prevent diabetes and obesity [2]. Steviol glycosides such as stevioside have

*Correspondence: pclee@ajou.ac.kr

Department of Molecular Science and Technology and Department of Applied Chemistry and Biological Engineering, Ajou University,

Woncheon-dong, Yeongtong-gu, Suwon 16499, South Korea therefore attracted the attention of the food and beverage industry. Steviol is biosynthesized from an isoprenoid precursor, isopentenyl pyrophosphate (IPP), which is synthesized through the methylerythritol 4-phosphate (MEP) pathway [3]. Three moles of IPP are condensed to form farnesyl diphosphate (FPP) by FPP synthase, and FPP is further condensed with one mole of IPP to form geranylgeranyl diphosphate (GGPP) by GGPP synthase (GGPPS). As shown in Fig. 1, GGPP is transformed to ent-copalyl diphosphate by copalyl diphosphate synthase (CDPS), and then ent-copalyl diphosphate is cyclized to ent-kaurene by kaurene synthase (KS). Finally,

c) The Author(s) 2020. This article is licensed under a Creative Commons Attribution 4.0 International License, which permits use, sharing, adaptation, distribution and reproduction in any medium or format, as long as you give appropriate credit to the original author(s) and the source, provide a link to the Creative Commons licence, and indicate if changes were made. The images or other third party material in this article are included in the article's Creative Commons licence, unless indicated otherwise in a credit line to the material. If material is not included in the article's Creative Commons licence and your intended use is not permitted by statutory regulation or exceeds the permitted use, you will need to obtain permission directly from the copyright holder. To view a copy of this licence, visit http://creativeco mmons.org/licenses/by/4.0/. The Creative Commons Public Domain Dedication waiver (http://creativecommons.org/publicdomain/ zero/1.0/) applies to the data made available in this article, unless otherwise stated in a credit line to the data. 


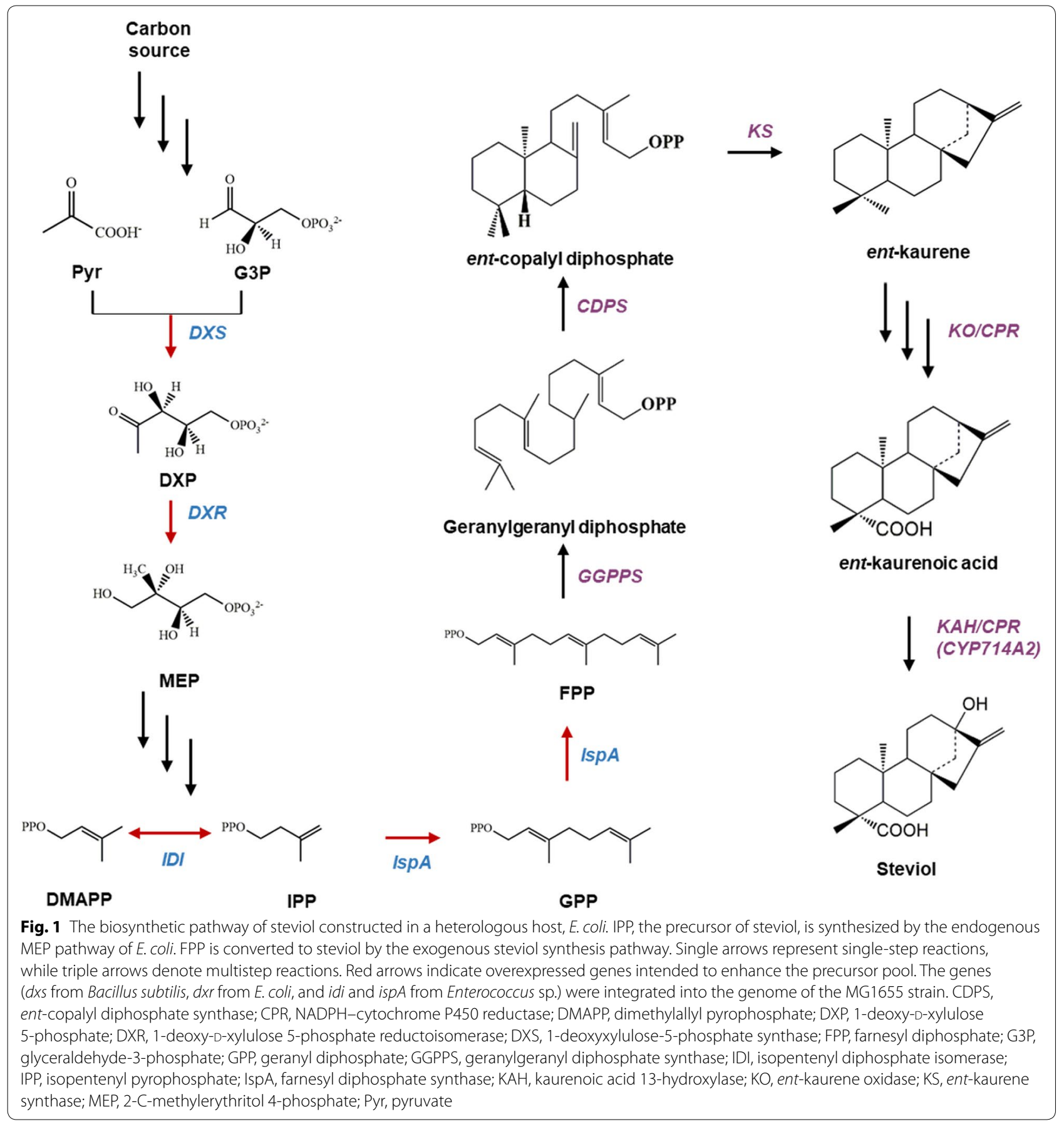

ent-kaurene is oxidized and hydroxylated by kaurene oxidase (KO) and kaurenoic acid 13-hydroxylase (KAH) with the formation of steviol [4].

Microbial production of steviol glycosides is regarded as a promising alternative to conventional methods such as extraction after open-field cultivation. Recently, efforts were made to produce ent-kaurene, ent-kaurenoic acid, steviol, and steviol glycosides in microorganisms by metabolic engineering $[5,6]$. Nevertheless, the titer of steviol is relatively low in metabolically engineered microorganisms, and therefore a steviol-biosynthetic pathway in heterologous microorganisms needs to be metabolically optimized. Some studies [6] have revealed that only a small amount of ent-kaurenoic acid is converted in vivo to steviol (Fig. 1), suggesting that the reaction of hydroxylation of ent-kaurenoic acid needs to be 
metabolically optimized in the steviol glycoside-biosynthetic pathway. It is known that the conversion yield of ent-kaurenoic acid to steviol is negligible when $\mathrm{KAH}$ from $S$. rebaudiana (srKAH) is expressed in Escherichia coli [6]. Accordingly, Wang and colleagues [6] have employed CYP714A2 from Arabidopsis thaliana instead of srKAH and achieved $15.4 \mathrm{mg} / \mathrm{L}$ steviol in E. coli. In addition, the same research group has reported that $1.8 \mathrm{~g} / \mathrm{L}$ ent-kaurene can be obtained by fed-batch fermentation (in a $5 \mathrm{~L}$ bioreactor) under optimized conditions.

Enzymes KO and KAH are cytochrome $\mathrm{P} 450$ proteins, and it is generally difficult to express functional P450 enzymes derived from plants in a heterologous bacterial system. Many plant P450 enzymes have a hydrophobic domain at the $\mathrm{N}$ terminus and contain transmembrane amino acid sequences, which are anchored in the endoplasmic reticulum membrane of plants [7, 8]. In addition, plant P450 enzymes need an auxiliary cytochrome P450 reductase (CPR), which transfers electrons from NADPH to P450 [9]. Plant P450 enzymes tend to be insoluble, and because the endoplasmic reticulum and CPR are not present in the heterologous $E$. coli system, functional expression of plant enzymes $\mathrm{KO}$ and $\mathrm{KAH}$ is difficult in E. coli. To overcome these challenges, there have been attempts to produce functional $\mathrm{P} 450$ proteins in $E$. coli via such approaches as $\mathrm{N}$-terminal amino acid sequence modifications and optimization of electron transfer efficiency [10-12].

Plasmid expression systems are useful for the reconstruction of biosynthetic pathways and usually give a high yield of a target product. On the other hand, plasmid expression systems have some disadvantages in large-scale fermentation, e.g., segregational or structural instability and a metabolic burden [13, 14]. An expensive antibiotic supplement is necessary to maintain plasmids in host cells during the cultivation. To resolve this problem, genome engineering techniques, such as $\lambda$ Red recombineering and CRISPR/Cas9, which can integrate genes into a chromosome, have been employed [15].

For higher steviol production, in the present study, our aim was to redesign a steviol-biosynthetic pathway by coexpression of enzymes GGPPS, CDPS, KS, KO, and $\mathrm{KAH}$-as a modular expression unit in E. coli-with an engineered MEP pathway. To increase the yield of steviol, engineering of $5^{\prime}$ untranslated region (UTR) sequences of $\mathrm{KS}$, modification of the $\mathrm{N}$-terminal sequences of $\mathrm{KO}$, and deletion of $g d h A$, which encodes glutamate dehydrogenase, were performed.

\section{Results and discussion}

\section{Engineering the ent-kaurene pathway in E. coli}

To investigate the effect of a GGPPS expression system (plasmid expression vs. a plasmid-free system) on the production of ent-kaurene, the MGI strain expressing genes $d x s, d x r, i d i$, and $i s p A$ was chosen as a platform strain for constructing two recombinant ent-kaureneproducing strains (MGI/GGPPS_CDPS_KS and MGIG/ CDPS_KS). The MGI strain was transformed with plasmid pSTVM_GCK, which coexpresses GGPPS, CDPS, and KS extrachromosomally (Table 2), resulting in the MGI/GGPPS_CDPS_KS strain. The genome-edited MGIG strain, which constitutively expresses GGPPS from the MGI genome (Fig. 2a), was transformed with plasmid pSTVM_CK, which coexpresses CDPS and KS extrachromosomally (Table 2), thus yielding the MGIG/ CDPS_KS strain. When two ent-kaurene-producing strains (MGI/GGPPS_CDPS_KS and MGIG/CDPS_KS) were cultured in flasks, the MGIG/CDPS_KS strain produced $146 \pm 6 \mathrm{mg} / \mathrm{L}$ ent-kaurene, whereas MGI/ GGPPS_CDPS_KS produced $189 \pm 10 \mathrm{mg} / \mathrm{L}$ ent-kaurene. Enhancement of the ent-kaurene production by GGPPS expression from the plasmid suggests that higher expression of GGPPS from the genome may increase the yield of ent-kaurene. Therefore, as one of the strategies for increasing GGPPS expression in the genome, engineering of the $5^{\prime}$-UTR was applied to GGPPS (Fig. 2b). The MGIUG strain expressing 5'-UTR_GGPPS in the MGI genome was constructed and transformed with pSTVM_CK. When the MGIUG/CDPS_KS strain was cultured in flasks, the production of ent-kaurene reached $195 \pm 9 \mathrm{mg} / \mathrm{L}$, which was comparable to the $189 \pm 10 \mathrm{mg} / \mathrm{L}$ obtained with GGPP expressed by a plasmid expression system (MGI/GGPPS_CDPS_KS).

Next, because the $5^{\prime}$-UTR-engineered GGPPS successfully increased the production of ent-kaurene, $5^{\prime}$-UTR-engineered genes CDPS and KS were constructed and further modified to be expressed from the genome of the MGIU strain (named MGIUK). When the production of ent-kaurene in the MGIUK strain was compared with that of MGI/GGPPS_CDPS_KS, which coexpresses GGPPS, CDPS, and KS from a plasmid, the MGIUK strain produced $205 \pm 35 \mathrm{mg} / \mathrm{L}$ entkaurene, whereas MGI/GGPPS_CDPS_KS produced $191 \pm 7 \mathrm{mg} / \mathrm{L}$ in flasks. This result indicates that the enzymes of the 5'-UTR-engineered ent-kaurene pathway when expressed from the genome were comparably functional as compared to the plasmid-based ent-kaurene pathway system developed in this study. The production of ent-kaurene ( $205 \pm 35 \mathrm{mg} / \mathrm{L})$ in flask fermentation by the genome-engineered MGIUK strain was also higher than the previously reported titers of $194.12 \mathrm{mg} / \mathrm{L}$ [6] and $179.6 \mathrm{mg} / \mathrm{L}$ [5] in an inducible or constitutive plasmid expression system. Notably, the growth of MGIUK was faster than that of MGI/GGPPS_CDPS_KS $\left(\mathrm{OD}_{600}\right.$ of $23 \pm 4.5$ vs. $20 \pm 4.1$ at $48 \mathrm{~h}$ of culture). This result suggests that a plasmid-free system may save cellular energy 

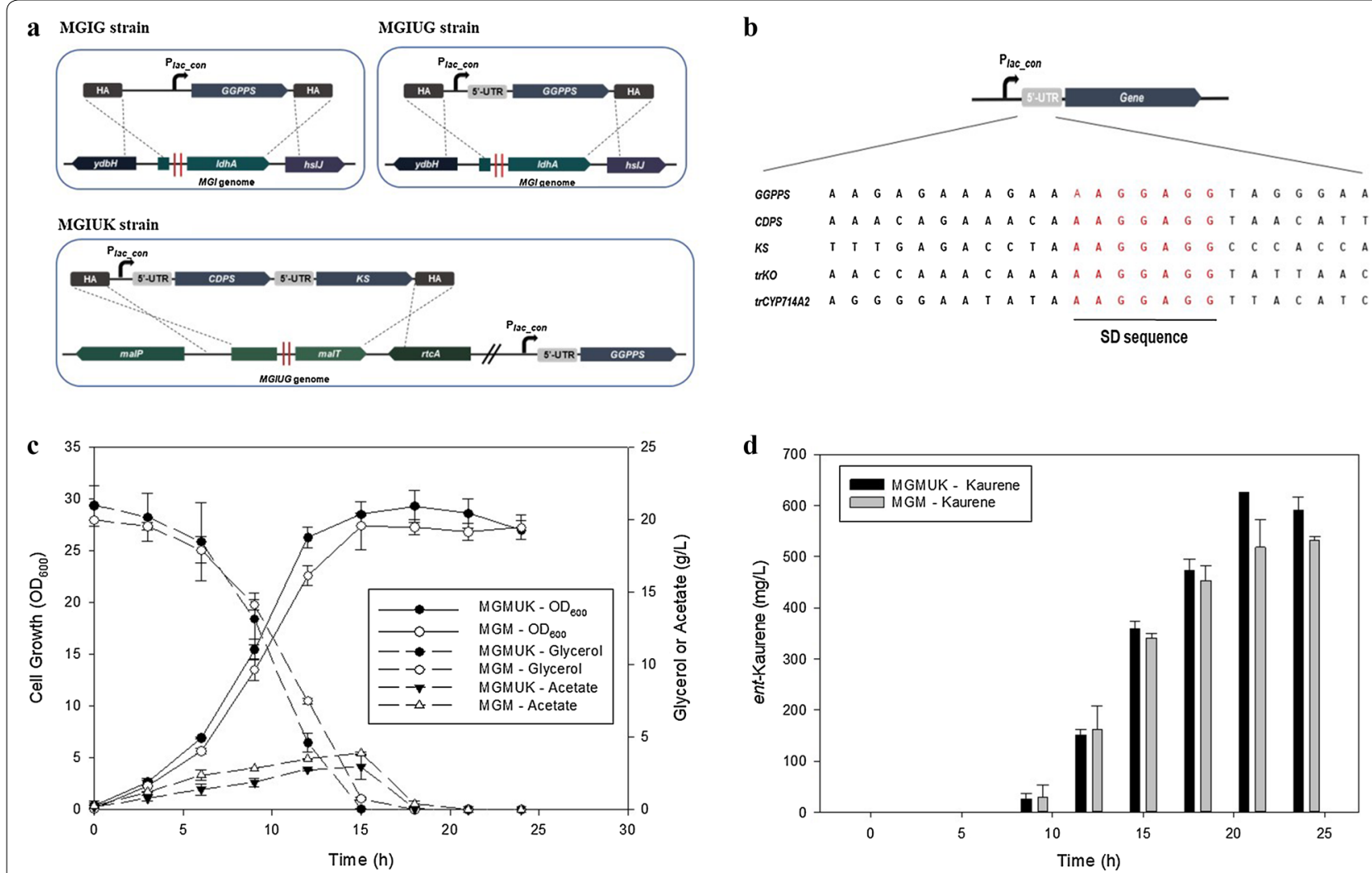

Fig. 2 Construction of genome-edited strains expressing $5^{\prime}$-UTR-engineered enzymes of the pathway. Cell growth and production of ent-kaurene in batch bioreactor fermentation are presented too. a Schemes of construction of strains MGIG, MGIUG, and MGIUK. $\mathbf{b}$ Redesign of the $5^{\prime}$-UTRs of GGPPS, CDPS, KS, trKO, and trCYP714A2. c Cell growth of strains MGIUK and MGI/GGPPS_CDPS_KS in batch fermentation with $20 \mathrm{~g} / \mathrm{L}$ glycerol as a carbon source. $\mathbf{d}$ Ent-kaurene production by strains MGIUK and MGI/GGPPS_CDPS_KS in batch fermentation. The results represent means from three independent experiments

and building blocks that are used to maintain and replicate the plasmids. To further investigate the growth and ent-kaurene production by the MGIUK strain, batch bioreactor fermentation was carried out with $20 \mathrm{~g} / \mathrm{L}$ glycerol as a carbon source (Fig. 2c). The MGIUK strain produced $623.6 \pm 3.0 \mathrm{mg} / \mathrm{L}$ ent-kaurene, which was $11 \%$ higher than the $531.5 \pm 7.1 \mathrm{mg} / \mathrm{L}$ ent-kaurene generated by MGI/GGPPS_CDPS_KS after $21 \mathrm{~h}$ of batch bioreactor fermentation (Fig. 2d). As observed in the flask fermentation, ent-kaurene production of the MGIUK strain was higher than the previously reported titer of $578 \mathrm{mg} / \mathrm{L}$ obtained via a constitutive plasmid expression system in batch fermentation [5]. The highest concentration of ent-kaurene reported so far is $1.8 \mathrm{~g} / \mathrm{L}$, obtained with an inducible plasmid in a fed-batch fermentation system [6]. Even though a direct comparison between our data and the results from Ref. [6] is problematic due to different fermentation modes (batch vs. fed-batch), the productivity of the MGIUK strain was better than that of the previously reported strain: $623.6 \pm 3.0 \mathrm{mg} / \mathrm{L}$ ent-kaurene after $21 \mathrm{~h}$ cultivation (Fig. 2d) vs. $\sim 600 \mathrm{mg} / \mathrm{L}$ ent-kaurene after $63 \mathrm{~h}$ cultivation [6]. The growth of MGIUK reached a maximum $\mathrm{OD}_{600}$ of 31 , whereas the growth of strain MGI/GGPPS_CDPS_KS reached a maximum $\mathrm{OD}_{600}$ of 28 at $18 \mathrm{~h}$ of culture. This observation confirms that the plasmid-free ent-kaurene-producing MGIUK strain is comparable with the plasmid-based ent-kaurene host, MGI/GGPPS_CDPS_KS.

\section{Engineering the ent-kaurenoic acid pathway in E. coli}

The pathway extension from ent-kaurene to ent-kaurenoic acid requires the $\mathrm{KO}$ enzyme and its electron transfer partner CPR. So far, two KOs (SrKO from $S$. rebaudiana and AtKO from $A$. thaliana [16]) have been mainly used for the reconstruction of the steviol and steviol glycoside pathway in microorganisms. To enhance the expression of $\mathrm{SrKO}$ and AtKO in the heterologous host $(E$. coli), the $\mathrm{N}$-terminal amino acid sequences of the two KOs were truncated and fused with the previously studied "MALLLAVF" sequence [17-19], thus resulting in trSrKO and trAtKO, respectively. CPR from A. thaliana (named AtCPR2) [6] served as an electron 
transfer partner for trSrKO and trAtKO in E. coli. During cultivation in flasks, the expression of trSrKO_AtCPR2 yielded less ent-kaurenoic acid $(13.5 \pm 1.4 \mathrm{mg} / \mathrm{L})$ as compared to native SrKO_AtCPR2 $(22.9 \pm 1.7 \mathrm{mg} / \mathrm{L})$ in the MGIUK strain. By contrast, trAtKO_AtCPR2 produced up to $31.8 \pm 1.7 \mathrm{mg} / \mathrm{L}$ ent-kaurenoic acid, whereas native AtKO_AtCPR2 did not produce ent-kaurenoic acid in the MGIUK strain (Fig. 3a). SDS-PAGE analysis confirmed that native AtKO was not expressed, which might explain why no production of ent-kaurenoic acid was observed when AtKO was used, while trAtKO was highly expressed in E. coli BL21 (DE3) (Fig. 3b). Given that trAtKO produced $40 \%$ more ent-kaurenoic acid than did native SrKO $(31.8 \pm 1.7$ vs. $22.9 \pm 1.7 \mathrm{mg} / \mathrm{L})$, further engineering of the $5^{\prime}$-UTR of trAtKO was carried out, and this gene was then expressed in the MGIUK strain. As expected, 5'-UTR-engineered trAtKO (named UtrAtKO) significantly increased ent-kaurenoic acid production up to $41.4 \pm 5 \mathrm{mg} / \mathrm{L}$ compared to $31.8 \pm 1.7 \mathrm{mg} / \mathrm{L}$ obtained by the expression of trAtKO in the MGIUK strain (Fig. 3a).

\section{The effect of the NADPH/NADP ${ }^{+}$ratio on the production of ent-kaurenoic acid}

It has been well documented that the cellular redox balance and cofactor availability significantly affect the yield of metabolites in microorganisms [20-22]. NADPH acts as a redox cofactor for $\mathrm{KO}$ in the steviol pathway. Therefore, because a higher NADPH/NADP ${ }^{+}$ratio increased the production of ent-kaurenoic acid, a MGIUKN strain was constructed by deletion of the $g d h A$ gene encoding glutamate dehydrogenase [21] in the MGIUK strain. As expected, the NADPH/NADP ${ }^{+}$ratio $(0.51 \pm 0.04)$ in the MGIUKN strain was $10 \%$ higher than that in
MGIUK $(0.44 \pm 0.01)$. The impact of the higher NADPH/ $\mathrm{NADP}^{+}$ratio on the production of ent-kaurenoic acid was investigated through flask fermentation, by cultivation of MGIUKN/UtrAtKO_AtCPR2, with MGIUK/ UtrAtKO_AtCPR2 serving as a control. MGIUKN/ UtrAtKO_AtCPR2 produced 22.5\% higher ent-kaurenoic acid concentration than did MGIUK/UtrAtKO_AtCPR2 (50.7 \pm 9.8 vs. $41.4 \pm 5 \mathrm{mg} / \mathrm{L}$ ), suggesting that the cellular redox balance is important for the conversion of ent-kaurene to ent-kaurenoic acid.

\section{Engineering the steviol pathway in E. coli}

The pathway extension from ent-kaurenoic acid to steviol was implemented via expression of CYP714A2 of A. thaliana instead of KAH of S. rebaudiana because CYP714A2 shows better performance than KAH does [6]. Likewise, to construct UtrAtKO, 5'-UTRengineered trCYP714A2 (named UtrCYP714A2) was constructed (Fig. 4a) and was coexpressed with UtrAtKO_AtCPR2 in strains MGIUKN and MGIUK. Similarly to the enhanced ent-kaurenoic acid production in the MGIUKN strain, MGIUKN/UtrAtKO UtrCYP714A2_AtCPR2 produced more steviol (Fig. 4b) than MGIUK/UtrAtKO_UtrCYP714A2_AtCPR2 did in flask cultures $(5.0 \pm 0.2$ vs. $4.2 \pm 1.1 \mathrm{mg} / \mathrm{L})$. As one of the strategies used to increase steviol production, the electron transfer between UtrCYP714A2 and AtCPR2 was improved by fusing them through a linker peptide. UtrCYP714A2 was structurally linked to trAtCPR2 (from which 72 amino acid residues were deleted at the $\mathrm{N}$ terminus) through one of three peptide linkers $(\text { GGGGS })_{\mathrm{n}=1-3}$. The presence and length of a flexible linker $(\text { GGGGS })_{n=1-3}$ significantly influenced steviol

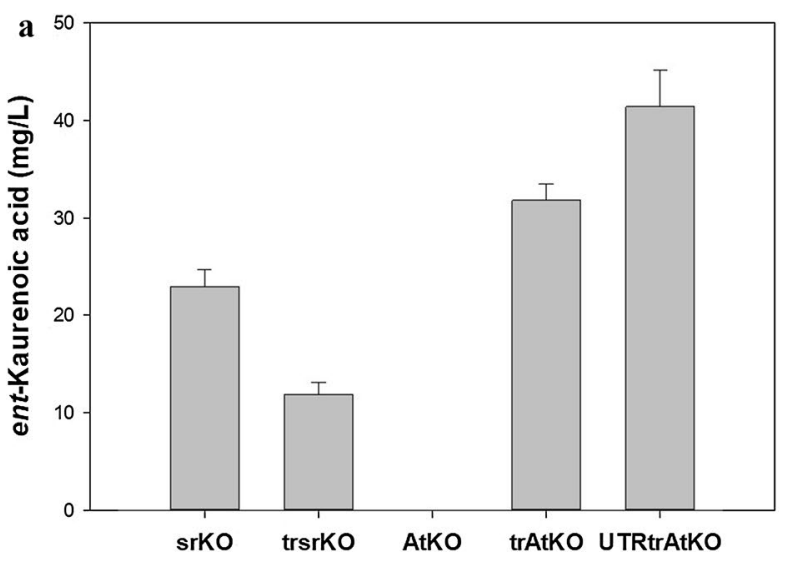

b

kDa $\quad$ M $\quad 1 \quad 2 \quad 3$

70

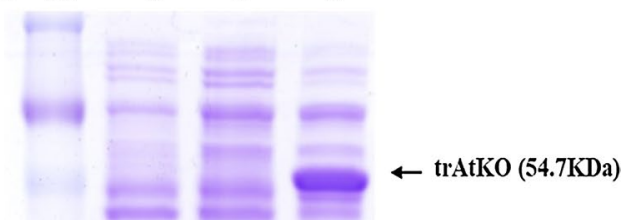

35

Fig. 3 Functional complementation of native KOs and N-terminally engineered KOs of $A$. thaliana and S. rebaudiana. SDS-PAGE analysis of the expression of these KOs is presented too. a The production of ent-kaurenoic acid in the MGIUK strains expressing SrKO, trSrKO, AtKO, trAtKO, and UtrAtKO. The results represent means from five independent experiments. b SDS-PAGE analysis [in a 10\% (w/v) gel] of a crude protein extract of $E$. coli BL21 (DE3) harboring pET21a (+), pET21a (+)_AtKO, and pET21a (+)_trAtKO. M: protein molecular weight markers, lane 1: pET21a (+), lane 2: pET21a (+)_AtKO, and lane 3: pET21a (+)_trAtKO 


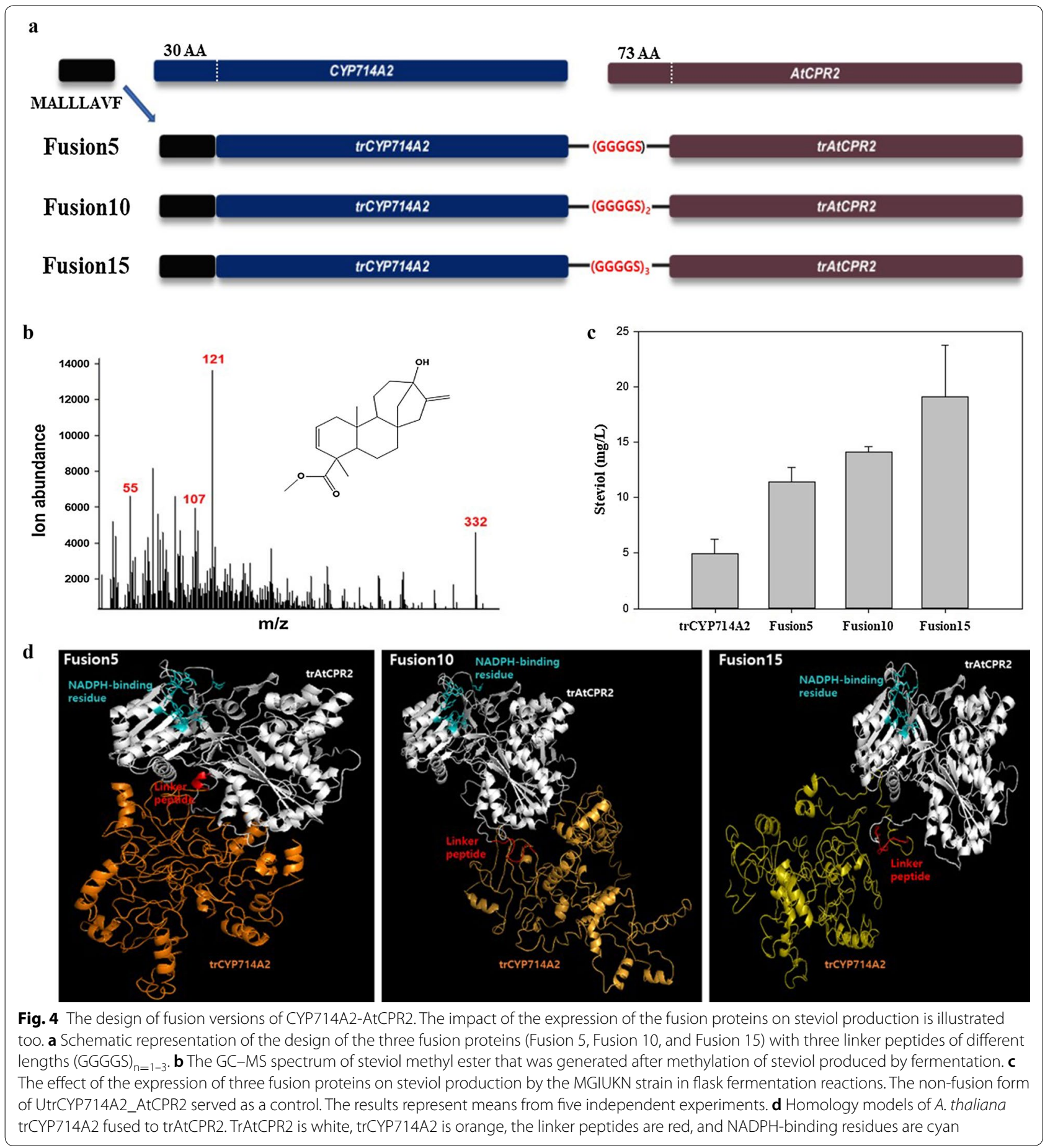

production in the MGIUKN strain. In comparison with the $5.0 \pm 0.2 \mathrm{mg} / \mathrm{L}$ steviol obtained by the expression of UtrCYP714A2_AtCPR2 without the fusion, the highest concentration of steviol, $19.1 \pm 4.6 \mathrm{mg} / \mathrm{L}$, was produced when fusion 15 [(GGGGS $)_{n=3}$ ] was expressed, followed by $14.1 \pm 0.5 \mathrm{mg} / \mathrm{L}$ [fusion $10,(\mathrm{GGGGS})_{\mathrm{n}=2}$ ] and $11.4 \pm 1.3 \mathrm{mg} / \mathrm{L}$ [fusion 5 , (GGGGS $)_{\mathrm{n}=1}$; Fig. 4c] .
These results and homology of the models of the three fusion proteins (Fig. 4c) mean that greater linker length does not interfere with the interaction of the two proteins (sterically) and increases the efficiency of electron transfer. The $19.1 \pm 4.6 \mathrm{mg} / \mathrm{L}$ steviol concentration yielded by fusion 15 was greater than a previously reported concentration, $15.47 \mathrm{mg} / \mathrm{L}$ [6]. To 
further investigate the growth and steviol production, batch bioreactor fermentation was performed with $20 \mathrm{~g} / \mathrm{L}$ glycerol as a carbon source for the MGIUKN strain expressing either UtrAtKO_Fusion15_AtCPR2 or UtrAtKO_UtrCYP714A2_AtCPR2. The growth of the two strains was similar, and reached maximum $\mathrm{OD}_{600}$ values of 28.6 and 28.1, respectively (Fig. 5a). MGIUKN/UtrAtKO_Fusion15_AtCPR2 produced the highest concentration of steviol $(38.4 \pm 1.7 \mathrm{mg} / \mathrm{L})$ at $20 \mathrm{~h}$ of culture, which was 4.3 -fold greater than the $8.8 \pm 0.3 \mathrm{mg} / \mathrm{L}$ concentration generated by the control MGIUKN/UtrAtKO_UtrCYP714A2_AtCPR2 strain (Fig. 5b). Because our steviol titer $(38.4 \pm 1.7 \mathrm{mg} / \mathrm{L})$ was obtained under suboptimal fermentation conditions, a future study on fermentation optimization, e.g., by means of medium components, may further raise the steviol titer.
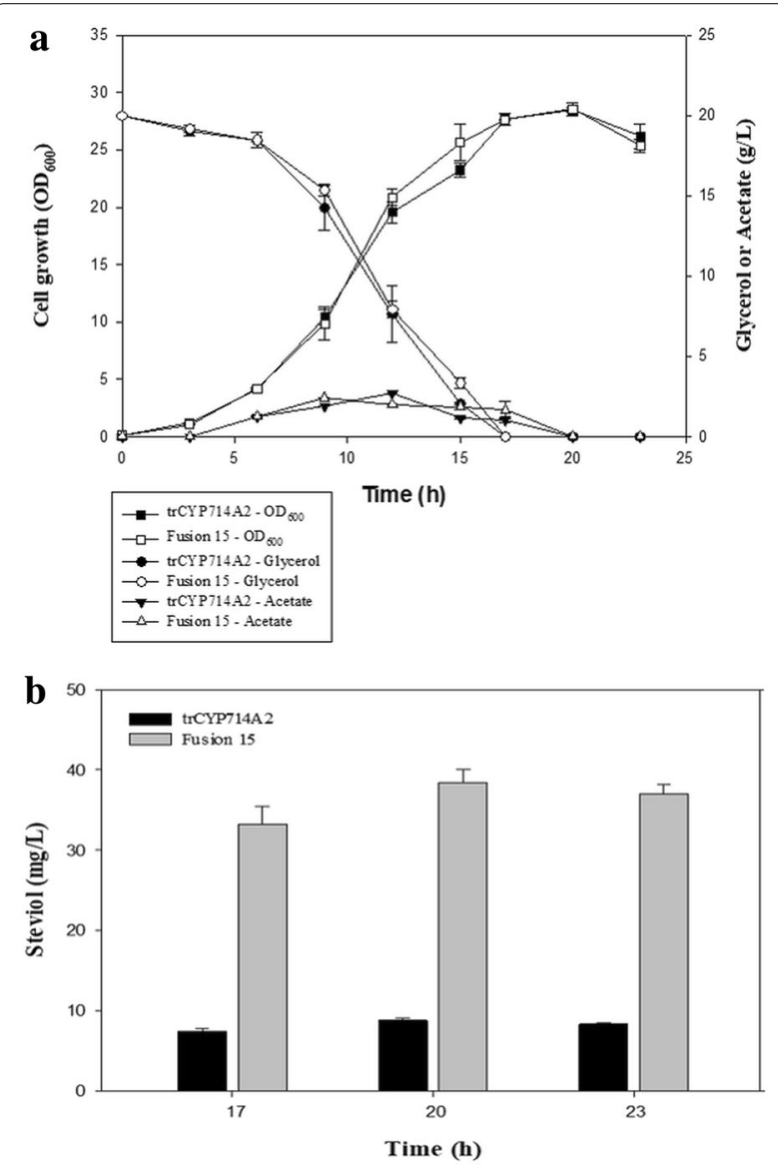

Fig. 5 Cell growth and production of steviol in batch bioreactor fermentation. a Cell growth of strains MGIUKN/UtrAtKO_ UtrCYP714A2_AtCPR2 and MGIUKN/UtrAtKO_Fusion15_AtCPR2 in batch fermentation with $20 \mathrm{~g} / \mathrm{L}$ glycerol as a carbon source. $\mathbf{b}$ Steviol production of strains UtrAtKO_UtrCYP714A2_AtCPR2 and MGIUKN/ UtrAtKO_Fusion15_AtCPR2 in batch fermentation. The results represent means from three independent experiments

\section{Conclusions}

In this study, a heterologous steviol-biosynthetic pathway was redesigned and reconstructed via a synthetic-biology approach to overproduce steviol in E. coli. $5^{\prime}$-UTR engineering, the fusion protein approach, and redox balancing improved the steviol titer in flask fermentation and bioreactor fermentation. The expression engineering of steviol-biosynthetic enzymes and genome engineering described here can serve as a basis for the production of terpenoids, including carotenoids, in microorganisms. Synthetic biology and metabolic engineering can be directly applied to the pathway engineering of steviol glycosides, which have a high value in the food industry.

\section{Methods}

Strains, plasmids, and culture conditions

All strains and plasmids used in this study are listed in Table 1. Plasmids pMP11 and pgRNA were provided by the Technical University of Denmark. For gene cloning, E. coli Top10 was cultivated in the Luria-Bertani (LB) medium $(10 \mathrm{~g} / \mathrm{L}$ tryptone, $5 \mathrm{~g} / \mathrm{L}$ yeast extract, and $5 \mathrm{~g} / \mathrm{L}$ $\mathrm{NaCl})$ at $37^{\circ} \mathrm{C}$ with shaking at $250 \mathrm{~g}$. For the preparation of steviol pathway products, recombinant $E$. coli strains were grown at $30{ }^{\circ} \mathrm{C}$ with shaking at $250 \mathrm{~g}$ in $500 \mathrm{~mL}$ flasks with the Terrific Broth (TB) medium (12 g/L tryptone, $24 \mathrm{~g} / \mathrm{L}$ yeast extract, $0.17 \mathrm{M} \mathrm{KH}_{2} \mathrm{PO}_{4}$, and $0.72 \mathrm{M}$ $\mathrm{K}_{2} \mathrm{HPO}_{4}$ ) supplemented with $10 \mathrm{~g} / \mathrm{L}$ glycerol. In particular, when the E. coli strain producing ent-kaurene was cultured, $20 \%(\mathrm{v} / \mathrm{v}) n$-dodecane was overlaid on the TB medium. Ampicillin $(100 \mu \mathrm{g} / \mathrm{mL})$ and chloramphenicol $(50 \mu \mathrm{g} / \mathrm{mL})$ were added as required.

\section{Construction of plasmids}

The primer sequences used for the construction of the plasmids are listed in Table 2. To obtain the optimized 5'-UTRs of GGPPS, CDPS, KS, trAtKO, and trCYP714A2, UTR designer [23] (http://sbi.poste ch.ac.kr/utr_designer) was utilized, and the optimized sequences of the $5^{\prime}$-UTRs are listed in Table 2. Each optimized $5^{\prime}$-UTR was fused to the corresponding gene by polymerase chain reaction (PCR), with gene-specific primers containing the $5^{\prime}$-UTR sequence and then was cloned into vectors pUCM [24] and pUCrop by Gibson assembly [25]. Three plasmids expressing GGPPS, CDPS, or KS (Table 1) served as templates for cloning the genes encoding GGPPS, CDPS, and KS.

To clone the genes encoding CYP714A2, AtKO, and AtCPR2 from $A$. thaliana, stem cells of $A$. thaliana were ground into a powder with a pestle in liquid nitrogen. Total RNA was extracted from the powder with the easy-BLUE ${ }^{\mathrm{TM}}$ RNA Extraction Kit (iNtRON Biotech, Korea) and then treated with DNase I (TaKaRa, Japan) 
Table 1 Strains and plasmids used in this study

\begin{tabular}{|c|c|c|}
\hline Strains or plasmids & Relevant properties & Source \\
\hline \multicolumn{3}{|l|}{ Strains } \\
\hline TOP10 & $\begin{array}{l}\mathrm{F}^{-} \text {mcrA } \Delta(\text { mrr-hsdRMS-merBC) } \varphi 80 \text { lacZ } \triangle M 15 \Delta \text { lacX74 recA1 araD139 } \Delta \text { (ara-leu)7697 galU } \\
\text { galK rpsL }\left(\mathrm{Str}^{\mathrm{R}}\right) \text { endA1 nupG }\end{array}$ & Invitrogen \\
\hline BL21 (DE3) & $\mathrm{F}^{-}$ompT gal dcm lon hsdS $\left(r_{B}^{-} m_{B}^{-}\right) \lambda\left(\right.$ DE3 [lacl lacUV5-T7p07 ind1 sam7 nin5]) $\left[\mathrm{malB}^{+}\right]_{\mathrm{K}-12}\left(\lambda^{\mathrm{S}}\right)$ & NEB \\
\hline MG1655 & $\mathrm{F}^{-}, \lambda^{-}, r p h-1$ & KCTC \\
\hline MGI & MG1655 $\Delta i / v G .:: d x s \Delta g / v C:: i d i \Delta y j b l:: i s p A \Delta a g a A V:: d x r$ & unpublished \\
\hline MGIG & $M G I \triangle / d h A:: G G P P S$ & This study \\
\hline MGIUG & MGI $\triangle / d h A .: U T R$ GGPPS & This study \\
\hline MGIUK & MGIUE $\triangle$ maIT::UTRCDPSKS & This study \\
\hline MGIUKN & MGIUK $\triangle g d h A$ & This study \\
\hline \multicolumn{3}{|l|}{ Plasmids } \\
\hline pUCM & Cloning vector derived from pUC19; constitutive lac promoter, $\mathrm{Amp}^{\mathrm{R}}$ & {$[25]$} \\
\hline pUCM_GGPPS & ColE1 ori, constitutive lac promoter, expressing GGPPS, Amp ${ }^{R}$ & [5] \\
\hline pUCM_CDPS & ColE1 ori, constitutive lac promoter, expressing CDPS, Amp ${ }^{R}$ & [5] \\
\hline pUCM_KS & ColE1 ori, constitutive lac promoter, expressing KS, Amp ${ }^{R}$ & [5] \\
\hline pUCM_GGPPS(U) & ColE1 ori, constitutive lac promoter, expressing GGPPS, synthetic 5'-UTR, Amp ${ }^{R}$ & This study \\
\hline pUCM_CDPS(U) & ColE1 ori, constitutive lac promoter, expressing CDPS, synthetic 5'-UTR, Amp ${ }^{R}$ & This study \\
\hline pUCM_KS(U) & ColE1 ori, constitutive lac promoter, expressing KS, synthetic $5^{\prime}-U T R, A m p^{R}$ & This study \\
\hline pSTVM2 & Cloning vector derived from pSTV29; constitutive lac promoter, $\mathrm{Cm}^{\mathrm{R}}$ & This study \\
\hline pSTVM_CK & p15A ori, constitutive lac promoter, expressing CDPS and $\mathrm{KS}, \mathrm{Cm}^{\mathrm{R}}$ & This study \\
\hline PSTVM_GCK & p15A ori, constitutive lac promoter, expressing GGPPS, CDPS, and KS, Cm ${ }^{R}$ & This study \\
\hline pSTVM_GCK(U) & $\begin{array}{l}\text { P15A ori, constitutive lac promoter, expressing GGPPS, CDPS and KS, synthetic 5'-UTR, } \\
\text { Cm }^{R}\end{array}$ & This study \\
\hline pUCrop & ColE1 ori, rop, Amp ${ }^{R}$ & This study \\
\hline pUCrop_AtKO & ColE1 ori, rop, constitutive lac promoter, expressing AtKO, Amp ${ }^{R}$ & This study \\
\hline pUCrop_AtCPR2 & ColE1 ori, rop, constitutive lac promoter, expressing AtCPR2, Amp ${ }^{R}$ & This study \\
\hline pUCrop_trAtKO & ColE1 ori, rop, constitutive lac promoter, expressing modified AtKO, Amp ${ }^{R}$ & This study \\
\hline pUCrop_trAtKO $(U)$ & $\begin{array}{l}\text { ColE1 ori, rop, constitutive lac promoter, expressing modified AtKO, synthetic 5'-UTR, } \\
\text { Amp }\end{array}$ & This study \\
\hline pUCrop_AtKO_AtCPR2 & ColE1 ori, rop, constitutive lac promoter, expressing AtKO and AtCPR2, Amp ${ }^{R}$ & This study \\
\hline pUCrop_trAtKO_AtCPR2 & ColE1 ori, rop, constitutive lac promoter, expressing modified AtKO and AtCPR2, Amp ${ }^{R}$ & This study \\
\hline pUCrop_SrKO_AtCPR2 & ColE1 ori, rop, constitutive lac promoter, expressing SrKO and AtCPR2, Amp ${ }^{R}$ & This study \\
\hline pUCrop_trSrKO_AtCPR2 & ColE1 ori, rop, constitutive lac promoter, expressing modified SrKO and AtCPR2, Amp ${ }^{R}$ & This study \\
\hline pUCrop_trAtKO(U)_AtCPR2 & $\begin{array}{l}\text { ColE1 ori, rop, constitutive lac promoter, expressing modified AtKO and AtCPR2, synthetic } \\
5^{\prime} \text {-UTR, Amp }\end{array}$ & This study \\
\hline pUCrop_trCYP714A2(U) & $\begin{array}{l}\text { ColE1 ori, rop, constitutive lac promoter, expressing modified CYP714A2, synthetic 5'-UTR, } \\
\text { Amp }{ }^{\mathrm{R}}\end{array}$ & This study \\
\hline pUCrop_Fusion5(U) & $\begin{array}{l}\text { ColE1 ori, rop, constitutive lac promoter, expressing modified CYP714A2 and AtCPR2, } \\
\text { chimera, synthetic 5'-UTR, Amp }{ }^{R}\end{array}$ & This study \\
\hline pUCrop_Fusion10(U) & $\begin{array}{l}\text { ColE1 ori, rop, constitutive lac promoter, expressing modified CYP714A2 and AtCPR2, } \\
\text { chimera, synthetic 5'-UTR, Amp }{ }^{R}\end{array}$ & This study \\
\hline pUCrop_Fusion15(U) & $\begin{array}{l}\text { ColE1 ori, rop, constitutive lac promoter, expressing modified CYP714A2 and AtCPR2, } \\
\text { chimera, synthetic 5'-UTR, Amp }{ }^{R}\end{array}$ & This study \\
\hline pUCrop_trAtKO(U)_AtCPR2_trCYP714A2(U) & $\begin{array}{l}\text { ColE1 ori, rop, constitutive lac promoter, expressing modified AtKO, AtCPR2 and modified } \\
\text { CYP714A2, synthetic 5'-UTR, Amp }{ }^{R}\end{array}$ & This study \\
\hline pUCrop_trAtKO(U)_AtCPR2_Fusion5(U) & $\begin{array}{l}\text { ColE1 ori, rop, constitutive lac promoter, expressing modified AtKO, AtCPR2 and fusion } \\
\text { protein, synthetic 5'-UTR, Amp }{ }^{R}\end{array}$ & This study \\
\hline pUCrop_trAtKO(U)_AtCPR2_Fusion10(U) & $\begin{array}{l}\text { ColE1 ori, rop, constitutive lac promoter, expressing modified AtKO, AtCPR2 and fusion } \\
\text { protein, synthetic 5'-UTR, Amp }{ }^{R}\end{array}$ & This study \\
\hline pUCrop_trAtKO(U)_AtCPR2_Fusion15(U) & $\begin{array}{l}\text { ColE1 ori, rop, constitutive lac promoter, expressing modified AtKO, AtCPR2 and fusion } \\
\text { protein, synthetic 5'-UTR, Amp }{ }^{R}\end{array}$ & This study \\
\hline $\mathrm{pET} 21 \mathrm{a}(+)$ & f1 ori, T7 promoter, C-terminal His-tag sequence, Amp ${ }^{R}$ & Novagen \\
\hline
\end{tabular}


Table 1 (continued)

\begin{tabular}{|c|c|c|}
\hline Strains or plasmids & Relevant properties & Source \\
\hline pET21a(+)_AtKO & f1 ori, T7 promoter, inducible expression of $\mathrm{His}_{6}$-tagged AtKO, Amp ${ }^{R}$ & This study \\
\hline pET21a(+)_trAtKO & f1 ori, T7 promoter, inducible expression of $\mathrm{His}_{6}$-tagged modified AtKO, Amp ${ }^{R}$ & This study \\
\hline pMP11 & pKD46 with constitutively expressed Cas9, aTc gRNA targeting ColE1 origin, Amp ${ }^{R}$ & [27] \\
\hline pgRNA & Constitutively expressed sgRNA & [27] \\
\hline pgRNA_IdhA & Constitutively expressed sgRNA targeting IdhA, ColE1 ori, $\mathrm{Cm}^{\mathrm{R}}$ & This study \\
\hline pgRNA_malT & Constitutively expressed sgRNA targeting gdhA, ColE1 ori, $\mathrm{Cm}^{\mathrm{R}}$ & This study \\
\hline pgRNA_gdhA & Constitutively expressed sgRNA targeting malT, ColE1 ori, $\mathrm{Cm}^{\mathrm{R}}$ & This study \\
\hline
\end{tabular}

at $37{ }^{\circ} \mathrm{C}$ for $30 \mathrm{~min}$. After inactivation of DNase I, $1 \mu \mathrm{g}$ of total RNA was subjected to cDNA synthesis using the ReverTraAce qPCR RT Kits (Toyobo, Japan). Genes encoding CYP714A2, AtKO, and AtCPR2 were amplified by PCR with gene-specific primers (Table 2). The three amplified genes were cloned into pUCrop, resulting in plasmids pUCrop_CYP714A2, pUCrop_AtKO, and pUCrop_AtCPR2. Assembly of two or three genes in one vector system, e.g., pUCrop_AtKO_AtCPR2 (Table 1), was carried out via the uracil excision cloning technology (USER) [26].

\section{Construction of an ent-kaurene pathway in the genome of $E$. coli}

The $E$. coli MG1655 strain expressing genes $d x s, d x r$, idi, and isp A (Table 1) served as a platform strain (named MGI) for engineering the ent-kaurene pathway. An MGIG strain expressing GGPPS was constructed by integration of a synthetic module expressing GGPPS into an $l d h A$ site in the MGI genome. Similarly, an MGIUG strain was constructed by integration of a synthetic module expressing 5'-UTR_GGPPS into an $l d h A$ site in the MGI genome. An MGIUK strain was created via integration of a synthetic module expressing $5^{\prime}$-UTR_CDPS and $5^{\prime}$-UTR_KS into a malT site in the MGIUG genome. The above-mentioned genome integration procedures were performed by CRISPR/Cas9 genome editing [27]. Linear donor DNA fragments containing combined $400 \mathrm{bp}$ homology arm sequences were constructed by overlap extension PCR with gene-specific primers (Table 2). To construct two guide RNA (gRNA) vectors (pgRNA_ldhA and pgRNA_malT), the pgRNA plasmid backbone was amplified by PCR with primers containing $20 \mathrm{bp}$ of a target-specific gRNA sequence. To improve the cutting efficiency of Cas9, the gRNA sequences were designed in the CHOPHOP software (http://chopchop.cbu.uib.no/). MGIG, MGIUG, and MGIUK were selected by colony $\mathrm{PCR}$, and the sequences of the edited genome sites of the three strains were verified by Sanger sequencing (Macrogen, Korea). The three genome-edited strains were cured of the plasmids by the addition of $200 \mathrm{ng} / \mathrm{ml}$ anhydrotetracycline and incubation at $37^{\circ} \mathrm{C}$.

\section{Construction and expression of $\mathrm{N}$-terminal mutant AtKO (trAtKO)}

The transmembrane region of AtKO was predicted by means of the online TMHMM software (http://www.cbs. dtu.dk/services/TMHMM/). The predicted region, consisting of 24 amino acid residues of AtKO, was replaced with an 8-mer peptide (MALLLAVF; derived from $17 \alpha$ bovine hydroxylase [6]), by PCR with primers (Table 2). The resulting $\mathrm{N}$-terminally modified trAtKO was cloned into the pET2 $1 \alpha(+)$ vector, resulting in pET21 $\alpha(+)$ trAtKO. Wild-type AtKO was also cloned into the pET $21 \alpha(+)$ vector, thus giving pET $21 \alpha(+) \_$AtKO. To analyze the expression levels of trAtKO and AtKO by SDS-PAGE, pET21 $\alpha(+)$ AtKO, pET21 $\alpha(+)$ _trAtKO, and the empty vector, pET2 $1 \alpha(+)$, were transfected into E. coli BL21 (DE3). The transformants were incubated at $30{ }^{\circ} \mathrm{C}$ and $250 \mathrm{~g}$ in $50 \mathrm{~mL}$ of the LB medium containing $100 \mu \mathrm{g} / \mathrm{mL}$ ampicillin. When optical density at $600 \mathrm{~nm}\left(\mathrm{OD}_{600}\right)$ reached $0.6-0.8,0.4 \mathrm{mM}$ isopropyl $\beta$-D1-thiogalactopyranoside (IPTG) was added to induce protein expression. After $3 \mathrm{~h}$ of induction, the cells were harvested and resuspended in $50 \mathrm{mM}$ Tris- $\mathrm{HCl}$ (pH 6.8). The resuspended cells were disrupted by ultrasonication on ice to extract total protein. Each sample was analyzed by SDS-PAGE in a 10\% (w/v) gel. Total-protein concentrations were determined by the Bradford assay.

\section{Deletion of $g d h A$ encoding a glutamate dehydrogenase, and measurement of NADP ${ }^{+}$and NADPH concentrations} An MGIKN strain with deletion of the $g d h A$ gene (encoding a glutamate dehydrogenase) was constructed by deletion of $g d h A$ from the genome of the MGIK strain using CRISPR/Cas9. Quantification of $\mathrm{NADP}^{+}$and NADPH concentrations in strains MGIK and MGIKN was carried out with NADP/NADPH Assay Kits (Abcam, UK). Cells in the log phase were harvested, and analytes were 
Table 2 Primers and other oligonucleotides used in this study

\begin{tabular}{|c|c|}
\hline Name & Sequence $\left(5^{\prime} \rightarrow 3^{\prime}\right)^{a, b}$ \\
\hline \multicolumn{2}{|l|}{ Primers for cloning } \\
\hline pUC_AtKO_F & $\begin{array}{l}\text { gcTCTAGAaggaggattacaaaatggc- } \\
\text { cttcttctccatga }\end{array}$ \\
\hline pUC_AtKO_R & $\begin{array}{l}\text { ataagaatGCGGCCGCttaagaacgccttg- } \\
\text { gattga }\end{array}$ \\
\hline pUC_AtCPR2_F & $\begin{array}{l}\text { gcTCTAGAaggaggattacaaaatgtc- } \\
\text { ctcttcttcttcttc }\end{array}$ \\
\hline pUC_AtCPR2_R & $\begin{array}{l}\text { ataagaatGCGGCCGCttaccatacatctctaa- } \\
\text { gatatc }\end{array}$ \\
\hline pUC_CYP714A2_F & $\begin{array}{l}\text { gcTCTAGAaggaggattacaaaatggagagc- } \\
\text { ctggtggtc }\end{array}$ \\
\hline pUC_CYP714A2_R & tcccCCCGGGttagacgacacggatcacga \\
\hline pUC_trAtKO_F & $\begin{array}{l}\text { gcTCTAGAaggaggattacaaaatggctt- } \\
\text { tacttctggcagtttttaagaaacttctctccttctc }\end{array}$ \\
\hline pUC_trCYP714A2_F & $\begin{array}{l}\text { gcTCTAGAaggaggattacaaaatggctt- } \\
\text { tacttctggcagtttttcgtgcggttgtcgagcag }\end{array}$ \\
\hline pET_AtKO_F & cgGGATCC catggecttcttctccatga \\
\hline pET_AtKO_R & ccgCTCGAGagaacgccttggattgataat \\
\hline pET_trAtKO_F & cgGGATCCatggctttacttctggcagt \\
\hline \multicolumn{2}{|l|}{ Primers for Gibson assembly } \\
\hline gibson_pV_F & ggccgctgcggtattttc \\
\hline gibson_pV_GGPPS_R & $\frac{\text { ttccctacctccttttctttctcttcgctcacaattc- }}{\text { cacacaa }}$ \\
\hline gibson_pV_CDPS_R & $\frac{\text { aatgttacctcctttgtttctgtttcgctcacaattc- }}{\text { cacacaa }}$ \\
\hline gibson_pV_KS_R & $\frac{\text { tggtgggcctcctttaggtctcaaac }}{\text { cacacaa }}$ \\
\hline gibson_pV_trAtKO_R & $\frac{\text { gttaatacctcctttttgtttggttcgctcacaattc- }}{\text { cacacaa }}$ \\
\hline gibson_pV_trCYP714A2_R & $\begin{array}{l}\text { gatgtaacctcctttatattcccctcgctcacaattc- } \\
\text { cacacaa }\end{array}$ \\
\hline gibson_GGPPS_F & $\begin{array}{l}\text { tgagcgaagagaaagaaaaggaggtagg- } \\
\text { gaaatggcgtttgaacagcgg }\end{array}$ \\
\hline gibson_CDPS_F & $\begin{array}{l}\text { tgagcgaaacagaaacaaaggaggtaacattat- } \\
\text { gaagaccggcttcatct }\end{array}$ \\
\hline gibson_KS_F & $\begin{array}{l}\text { tgagcgtttgagacctaaaggaggeccaccaat- } \\
\text { gaatctttcactatgcatc }\end{array}$ \\
\hline gibson_trAtKO_F & $\begin{array}{l}\text { tgagcgaaccaaacaaaaaggaggtattaacatg- } \\
\text { gctttacttctggcagt }\end{array}$ \\
\hline gibson_trCYP714A2_F & $\begin{array}{l}\text { tgagcaggggaatataaaggaggttacatcatg- } \\
\text { gctttacttctggcag }\end{array}$ \\
\hline gibson_insert_R & aataccgcacagatgcgtaa \\
\hline gibson_Fusion5_AtCPR2_F & ggtggcggcggaagcaggagatccggttctgg \\
\hline $\begin{array}{l}\text { gibson_Fusion5_- } \\
\text { trCYP714A2_R }\end{array}$ & $\begin{array}{l}\text { cggatctcctgcttccgecgecaccgacgacacg- } \\
\text { gatcacgac }\end{array}$ \\
\hline gibson_Fusion10_AtCPR2_F & $\begin{array}{l}\text { gtggcggtagtggcggtggtggaagtaggaga- } \\
\text { tccggttctgg }\end{array}$ \\
\hline $\begin{array}{l}\text { gibson_Fusion10_ } \\
\operatorname{trCYP714A2\_ R}\end{array}$ & $\begin{array}{l}\text { cttccaccaccgccactaccgccaccaccgac- } \\
\text { gacacggatcacgac }\end{array}$ \\
\hline gibson_Fusion15_AtCPR2_F & $\begin{array}{l}\text { caggtggtgggggatctggtggcggtggcag- } \\
\text { taggagatccggttctgg }\end{array}$ \\
\hline $\begin{array}{l}\text { gibson_Fusion15 } \\
\operatorname{trCYP714A2\_ R}\end{array}$ & $\begin{array}{l}\text { ccgccaccagatcccccaccacctgacccccctc- } \\
\text { ctccgacgacacggatcacgac }\end{array}$ \\
\hline
\end{tabular}

Table 2 (continued)

\begin{tabular}{|c|c|}
\hline Name & Sequence $\left(5^{\prime} \rightarrow 3^{\prime}\right)^{\mathrm{a}, \mathrm{b}}$ \\
\hline \multicolumn{2}{|l|}{ Primers for subcloning } \\
\hline pSTVM2-sub-USER-3-F & agacagucataagtgcgg \\
\hline pSTVM2-sub-USER-1-R & atgcaacucgtaggacag \\
\hline pUC- sub-USER-3-F & agacagucaatctgctctgatgcc \\
\hline pUC- sub-USER-1-R & atgcaacuca taatgaatcggccaac \\
\hline pUC-sub-USER-1-F & agttgcaucccgactggaaagcg \\
\hline pUC-sub-USER-2-F & atccatgucccgactggaaagcg \\
\hline pUC-sub-USER-5-F & atatgcgaucccgactggaaagcg \\
\hline pUC-sub-USER-2-R & acatggauatgcggtgtgaaatacc \\
\hline pUC-sub-USER-5-R & atcgcatauatgcggtgtgaaataccg \\
\hline pUC-sub-USER-3-R & actgtcuatgcggtgtgaaataccg \\
\hline \multicolumn{2}{|c|}{ Primers for genome editing } \\
\hline IdhA_up_F & aaacctttacgcgtaatgcg \\
\hline IdhA_up_R & ctttccagtcgtgctataaacggcgagtt \\
\hline GGPPS_F & tttatagcacgactggaaagcgggcag \\
\hline GGPPS_R & gcaagattaaagaaaataccgcagcggcc \\
\hline IdhA_Down_F & ggtattttctttaatcttgccgctcccc \\
\hline IdhA_Down_R & ggttagcgcacatcatacg \\
\hline malT_up_F & aaaaatggccgttgcgtatt \\
\hline malT_up_R & $\begin{array}{l}\text { tttccagtcgggacatggatagttaatcacttcact- } \\
\text { gtgga }\end{array}$ \\
\hline CDPS_F & atccatgtcccgactggaaagcg \\
\hline CDPS_R & tcatattacaatctcgaacacc \\
\hline KS_F & $\begin{array}{l}\text { tgttcgagattgtaatatgatttgagacctaaa- } \\
\text { ggaggc }\end{array}$ \\
\hline KS_R & actgtctatgcggtgtgaaataccg \\
\hline malT_Down_F & $\begin{array}{l}\text { tttcacaccgcatagacagtcaattgctgaagat- } \\
\text { gatggg }\end{array}$ \\
\hline malT_Down_R & gccgggtaataccgtctc \\
\hline Confirm_GGPPS_F & cggattgaagcggcaatg \\
\hline Confirm_GGPPS_R & tgcccagcgtctcggcat \\
\hline Confirm_CDPS/KS_F & aactcatcctcaataccaac \\
\hline Confirm_CDPS/KS_R & ggctacccatgctgtgtc \\
\hline Confirm_gdhA_F & ttatggctttacgcgccgc \\
\hline Confirm_gdhA_R & gggacaattgaagaagaact \\
\hline \multicolumn{2}{|c|}{ Oligonucleotides for deletion of gdhA } \\
\hline gdhA-MAGE & $\begin{array}{l}\text { aatatataagggttttatatctatggatcagacat- } \\
\text { attctctggcgcagggtgtgatttaagttgtaaat- } \\
\text { gcctgatggc }\end{array}$ \\
\hline
\end{tabular}

a Capital letters indicate restriction sites

b Underlining denotes $5^{\prime}$-UTR sequences

extracted via two freeze-thaw cycles in NADP/NADPH extraction buffer.

\section{Construction of the artificial self-sufficient trCYP714A2-AtCPR2 fusion protein}

The transmembrane region of NADPH cytochrome P450 reductase 2 of $A$. thaliana (AtCPR2) was predicted using 
the TMHMM program. Seventy-two amino acid residues from the $\mathrm{N}$ terminus of AtCPR2 were removed by PCR with specific primers (Table 2), thus yielding trAtCPR2. In a similar way, the N-terminal sequence of CYP714A2 was removed by PCR. The $\mathrm{N}$ terminus of trAtCPR2 was fused to the $\mathrm{C}$ terminus of $\operatorname{trCYP714A2}$ through a flexible linker of varied length, (GGGGS) ${ }_{n=1-3}$, by Gibson assembly. The resulting fusion proteins were named Fusion 5, Fusion 10, and Fusion 15. The primer sequences used to construct the fusion proteins are provided in Table 2.

\section{Batch bioreactor fermentation}

Strains MGI and MGIUK were utilized for the production of ent-kaurene, and the MGIUKN strain was used for the production of steviol in batch bioreactor fermentation. Seed cultures of strains MGI, MGIUK, and MGIUKN were prepared by inoculation into $4 \mathrm{~mL}$ of the $\mathrm{LB}$ medium containing appropriate antibiotics at $30{ }^{\circ} \mathrm{C}$ with shaking at $250 \mathrm{~g}$ for $10 \mathrm{~h}$. The seed cultures were transferred to $100 \mathrm{~mL}$ of the TB medium containing appropriate antibiotics until $\mathrm{OD}_{600}$ reached $2-3$; then, the precultures were transferred into a $3 \mathrm{~L}$ jar bioreactor (BioFlo 320, Eppendorf, USA) containing $1 \mathrm{~L}$ of the TB medium supplemented with $20 \mathrm{~g} / \mathrm{L}$ glycerol and appropriate antibiotics; $20 \%(\mathrm{v} / \mathrm{v}) n$-dodecane was added into fermentation medium. Fermentation was carried out at $30{ }^{\circ} \mathrm{C}$ at an air flow rate of $1.5 \mathrm{vvm}$. The dissolved-oxygen level was maintained at $30 \%$ by means of air supply or a mixture of air and pure $\mathrm{O}_{2}$ and via adjustment of the agitation rate between 300 and $600 \mathrm{rpm}$. pH was automatically maintained at 7.0 by the addition of $24 \%$ (v/v) $\mathrm{NH}_{4} \mathrm{OH}$ and $2 \mathrm{~N} \mathrm{HCl}$. Cell growth was monitored at a wavelength of $600 \mathrm{~nm}$ on a SPECTRAmax PLUS384 instrument (Molecular Devices, USA).

\section{Extraction and analysis of products}

To quantify ent-kaurene, the $n$-dodecane layer in the bacterial culture was recovered by centrifugation, and $50 \mu \mathrm{L}$ of the $n$-dodecane was diluted with $450 \mu \mathrm{L}$ of ethyl acetate (EA). To extract ent-kaurenoic acid and steviol, fermentation broth containing cells was ultrasonicated and extracted twice with an equal volume of EA. After centrifugation for $5 \mathrm{~min}$ at $14,000 \mathrm{~g}$, the organic phase was collected and dried in an EZ-2 plus centrifugal evaporator (Genevac, UK). The dried samples were dissolved in $50 \mu \mathrm{L}$ of $\mathrm{MeOH}$ and then methylated with diazomethane in diethyl ether. Ent-kaurene, kaurenoic acid methyl ester, and steviol methyl ester were resuspended in EA and analyzed by gas chromatography with mass spectrometry (GC-MS) on Agilent 7890A, 5874C (Agilent Technologies, USA) equipped with an HP-5MS column (30 $\mathrm{m} \times 0.25 \mathrm{~mm} \times 0.25 \mu \mathrm{m}$, Agilent Technologies). The GC-MS operational conditions were as follows: initial temperature $80{ }^{\circ} \mathrm{C}$ for $1 \mathrm{~min}$, ramp up to $245{ }^{\circ} \mathrm{C}$ at $15^{\circ} \mathrm{C} /$ min, and ramp up to $300{ }^{\circ} \mathrm{C}$ at $5{ }^{\circ} \mathrm{C} / \mathrm{min}$; the flow rate of helium was $1.2 \mathrm{~mL} / \mathrm{min}$. Organic acid and glycerol concentrations in culture media were quantified using an Agilent 1200 HPLC system equipped with a refractive index detector (Agilent Technologies) and an Aminex HPX-87H column (Bio-Rad, USA) with $4 \mathrm{mM} \mathrm{H}_{2} \mathrm{SO}_{4}$ as the mobile phase. The flow rate was $0.7 \mathrm{~mL} / \mathrm{min}$, and column temperature was kept at $50{ }^{\circ} \mathrm{C}$.

\section{Homology modeling and structural analysis}

Fusion proteins were modeled with 10 PDB template structures by means of I-TASSER [28]. All structures were visualized in the PyMOL software (http://www. pymol.org). NADPH-binding sites of the fusion proteins were predicted with $\mathrm{COACH}$ [29].

\section{Acknowledgements \\ The authors thank Prof. Sang Yup Lee, KAIST, South Korea, for discussion.}

\section{Authors' contributions}

JHM and PCL planned the work. JHM and PCL conceived and designed the experiments. JHM, KL and JHL executed all the experiments. JHM, KL, JHL and PCL analyzed the results, compiled, reviewed, and revised the manuscript. All authors read and approved the final manuscript.

\section{Funding}

The work was supported by the National Research Foundation of Korea (NRF) funded by the Ministry of Education, Science and Technology [Grant Numbers 2017R1A2B4011899 and 2012M1A2A2026562].

\section{Availability of data and materials}

Not applicable.

Ethics approval and consent to participate

Not applicable.

Consent for publication

Not applicable.

Competing interests

The authors declare that they have no competing interests.

Received: 10 August 2019 Accepted: 21 January 2020

Published online: 03 February 2020

References

1. Prakash I, DuBois G, Clos J, Wilkens K, Fosdick L. Development of rebiana, a natural, non-caloric sweetener. Food Chem Toxicol. 2008;46:S75-82.

2. Pol J, Hohnova B, Hyotylainen T. Characterisation of Stevia rebaudiana by comprehensive two-dimensional liquid chromatography time-of-flight mass spectrometry. J Chromatogr A. 2007;1150:85-92.

3. Totté N, Charon L, Rohmer M, Compernolle F, Baboeuf I, Geuns JM. Biosynthesis of the diterpenoid steviol, an ent-kaurene derivative from Stevia rebaudiana Bertoni, via the methylerythritol phosphate pathway. Tetrahedron Lett. 2000;41:6407-10.

4. Brandle JE, Telmer PG. Steviol glycoside biosynthesis. Phytochemistry. 2007;68:1855-63.

5. Kong MK, Kang H-J, Kim JH, Oh SH, Lee PC. Metabolic engineering of the Stevia rebaudiana ent-kaurene biosynthetic pathway in recombinant Escherichia coli. J Biotechnol. 2015;214:95-102. 
6. Wang J, Li S, Xiong Z, Wang Y. Pathway mining-based integration of critical enzyme parts for de novo biosynthesis of steviolglycosides sweetener in Escherichia coli. Cell Res. 2016;26:258-61.

7. Biggs BW, Lim CG, Sagliani K, Shankar S, Stephanopoulos G, De Mey M, Ajikumar PK. Overcoming heterologous protein interdependency to optimize P450-mediated Taxol precursor synthesis in Escherichia coli. Proc Natl Acad Sci. 2016:113(12):3209-14.

8. Brignac-Huber LM, Park JW, Reed JR, Backes WL. Cytochrome P450 organization and function are modulated by endoplasmic reticulum phospholipid heterogeneity. Drug Metab Dispos. 2016;44:1859-66.

9. Jensen K, Møller BL. Plant NADPH-cytochrome P450 oxidoreductases. Phytochemistry. 2010;71:132-41

10. Sadeghi SJ, Gilardi G. Chimeric P450 enzymes: activity of artificial redox fusions driven by different reductases for biotechnological applications. Biotechnol Appl Biochem. 2013;60:102-10

11. Bakkes PJ, Riehm JL, Sagadin T, Rühlmann A. Engineering of versatile redox partner fusions that support monooxygenase activity of functionally diverse cytochrome P450s. Sci Rep. 2017;7:1-13.

12. Choi KY, Jung EO, Yun H, Yang YH, Kim BG. Engineering class I cytochrome P450 by gene fusion with NADPH-dependent reductase and S. avermitilis host development for daidzein biotransformation. Appl Microbiol Biotechnol. 2014;98:8191-200.

13. Jones KL, Kim S-W, Keasling J. Low-copy plasmids can perform as well as or better than high-copy plasmids for metabolic engineering of bacteria. Metab Eng. 2000;2:328-38.

14. Birnbaum S, Bailey J. Plasmid presence changes the relative levels of many host cell proteins and ribosome components in recombinant Escherichia coli. Biotechnol Bioeng. 1991;37:736-45

15. Pyne ME, Moo-Young M, Chung DA, Chou CP. Coupling the CRISPR/Cas9 system to lambda Red recombineering enables simplified chromosomal gene replacement in Escherichia coli. Appl Environ Microbiol. 2015:81:5103-14

16. Helliwell CA, Poole A, Peacock WJ, Dennis ES. Arabidopsis ent-kaurene oxidase catalyzes three steps of gibberellin biosynthesis. Plant Physiol. 1999;119:507-10.

17. Barnes HJ, Arlotto MP, Waterman MR. Expression and enzymatic activity of recombinant cytochrome P450 17 alpha-hydroxylase in Escherichia coli. Proc Natl Acad Sci. 1991:88:5597-601.

18. Ajikumar PK, Xiao W-H, Tyo KE, Wang Y, Simeon F, Leonard E, Mucha O, Phon TH, Pfeifer B, Stephanopoulos G. Isoprenoid pathway optimization for Taxol precursor overproduction in Escherichia coli. Science. 2010;330:70-4

19. Rouck JE, Biggs BW, Kambalyal A, Arnold WR, De Mey M, Ajikumar PK, Das A. Heterologous expression and characterization of plant Taxadiene5a-Hydroxylase (CYP725A4) in Escherichia coli. Protein Expr Purif. 2017;132:60-7.

20. Lee HC, Kim JS, Jang W, Kim SY. High NADPH/NADP + ratio improves thymidine production by a metabolically engineered Escherichia coli strain. J Biotechnol. 2010;149:24-32.

21. Alper H, Jin YS, Moxley JF, Stephanopoulos G. Identifying gene targets for the metabolic engineering of lycopene biosynthesis in Escherichia coli. Metab Eng. 2005;7:155-64.

22. Zhao J, Li Q, Sun T, Zhu X, Xu H, Tang J, Zhang X, Ma Y. Engineering central metabolic modules of Escherichia coli for improving $\beta$-carotene production. Metab Eng. 2013;17:42-50.

23. Seo SW, Yang J-S, Kim I, Yang J, Min BE, Kim S, Jung GY. Predictive design of mRNA translation initiation region to control prokaryotic translation efficiency. Metab Eng. 2013;15:67-74.

24. Gibson DG, Young L, Chuang R-Y, Venter JC, Hutchison CA III, Smith HO. Enzymatic assembly of DNA molecules up to several hundred kilobases. Nat Methods. 2009;6:343.

25. Kim SH, Park YH, Schmidt-Dannert C, Lee PC. Redesign, reconstruction, and directed extension of the Brevibacterium linens C40 carotenoid pathway in Escherichia coli. Appl Environ Microbiol. 2010;76:5199-206.

26. Cavaleiro AM, Kim SH, Seppala S, Nielsen MT, Nørholm MH. Accurate DNA assembly and genome engineering with optimized uracil excision cloning. ACS Synth Biol. 2015;4:1042-6.

27. Mehrer CR, Incha MR, Politz MC, Pfleger BF. Anaerobic production of medium-chain fatty alcohols via a $\beta$-reduction pathway. Metabol Eng. 2018;48:63-71.

28. Zhang Y. I-TASSER server for protein 3D structure prediction. BMC Bioinf 2008;9:40.

29. Wu Q, Peng Z, Zhang Y, Yang J. COACH-D: improved protein-ligand binding sites prediction with refined ligand-binding poses through molecular docking. Nucleic Acids Res. 2018;46:W438-42.

\section{Publisher's Note}

Springer Nature remains neutral with regard to jurisdictional claims in published maps and institutional affiliations.
Ready to submit your research? Choose BMC and benefit from:

- fast, convenient online submission

- thorough peer review by experienced researchers in your field

- rapid publication on acceptance

- support for research data, including large and complex data types

- gold Open Access which fosters wider collaboration and increased citations

- maximum visibility for your research: over 100M website views per year

At BMC, research is always in progress.

Learn more biomedcentral.com/submissions 